\title{
Glycogen storage disease due to phosphoglycerate kinase 1 deficiency
}

INSERM

\section{Source}

INSERM. (1999). Orphanet: an online rare disease and orphan drug data base. Glycogen storage disease due to phosphoglycerate kinase 1 deficiency. ORPHA:713

Phosphoglycerate kinase (PGK) deficiency is a metabolic disorder characterized by variable combinations of nonspherocytic hemolytic anemia, myopathy, and various central nervous system abnormalities. 